\title{
Experimental and Numerical Study on Mechanical Properties and Deformation Behavior of Beishan Granite considering Heterogeneity
}

\author{
Z. H. Wang $\mathbb{D}^{1,2}$ Y. L. Tan, ${ }^{1,2}$ S. M. Li, ${ }^{3}$ T. Z. Wang, ${ }^{4}$ and X. C. $\mathrm{Wu}^{5}$ \\ ${ }^{1}$ State Key Laboratory of Mining Disaster Prevention and Control Cofounded By Shandong Province and the Ministry of \\ Science and Technology, Shandong University of Science and Technology, Qingdao 266590, Shandong, China \\ ${ }^{2}$ College of Energy and Mining Engineering, Shandong University of Science and Technology, Qingdao 266590, Shandong, China \\ ${ }^{3}$ Jinan Engineering Polytechnic, Jinan 250200, Shandong, China \\ ${ }^{4}$ China Construction Eighth Engineering Division Corp. Ltd. Construction Branch, Qingdao 266590, Shandong, China \\ ${ }^{5}$ Design and Research Institute of Tianyuan Construction Group Co. Ltd., Linyi 276000, Shandong, China
}

Correspondence should be addressed to Z. H. Wang; skd996340@sdust.edu.cn

Received 27 October 2020; Revised 5 April 2021; Accepted 13 April 2021; Published 23 April 2021

Academic Editor: Yu-Wei Chen

Copyright (c) 2021 Z. H. Wang et al. This is an open access article distributed under the Creative Commons Attribution License, which permits unrestricted use, distribution, and reproduction in any medium, provided the original work is properly cited.

Disposal of high-level radioactive waste (HLW) deep underground is one of the most challenging research subjects in rock engineering. In China, Beishan granite is usually chosen as host rock for the construction of the HLW repository. In this study, mechanical tests are conducted on Beishan granite and the stress-strain state during the complete failure process is analyzed by numerical simulation. The results show that the tensile strength and uniaxial compressive strength of Beishan granite are 8.66 and $162.9 \mathrm{MPa}$, respectively. Dilatancy appears when the stress reaches about $81 \%$ of the peak strength. Heterogeneity is introduced by Weibull distribution in numerical simulation. With the increase of homogenization degree, the degraded elements are more easily to concentrate locally. Based on experimental and numerical simulation results, it is noticeable that the sample volume is basically in the state of compaction before reaching the peak strength. The elements are more likely to show expansion, and the splitting failure dominates the destroy mode when the confining pressure is relatively low. With increasing confining pressure, more and more degraded elements are concentrated in the shear band, which develops from the surface to the interior of the sample during loading. Therefore, the granite shows ductile mechanical response characteristics when the confining pressure is relatively high. The results are instructive for the construction of the repository.

\section{Introduction}

High-level radioactive waste (HLW) is one of the most harmful pollutants in the world. Currently, the most feasible way to isolate the HLW from the biosphere is to seal them in a geological disposal repository underground for 500-1000 m. Granite, characterized by low permeability and high strength, is a potential host rock for HLW. It is reported that Beishan granite is chosen as the host rock of a HLW repository in China [1-3]. Therefore, understanding the mechanical response and deformation behavior of Beishan granite is of significant importance for the safety and longterm stability of a repository.
As a natural material, rocks contain microcracks. It has been widely recognized that the growth of microcracks associated with crack propagation and coalescence can ultimately cause crystalline rock failure [4-16]. Wawersik and Brace conducted compression experiments on Westerly granite, indicating that at low confining pressure faulting in granite occurs only in the post-failure region beyond the peak of the stress-strain curves [5]. Hadley measured crack lengths and widths in virgin and pre-stressed Westerly granite by using the scanning electron microscope. It is found that the average aspect ratio of stress-induced cracks increases with stress [7]. Oda et al. studied the evolution of stress-induced cracks and failure mechanism in terms of the 
invariants of crack tensor. It demonstrates that the density of the stress-induced cracks increases linearly with increasing inelastic volumetric strain [11]. However, the crack propagation process is difficult to be captured under experimental tests.

From another view, the variation of rock volume is closely related to the propagation of microcracks. As a result, rocks will show the most direct performance of compaction or expansion [17-20]. Brace et al. measured volume change of granite during deformation in triaxial compression. It reveals that open fractures propagate parallel with the orientation of maximum compression [17]. Besides, the dilatancy of specimens is directly proportional to fracturing [18] and occurs within about 10 percent of the fracture stress difference [19]. In addition, the failure mode of crystalline rocks is highly related to cracking, resulting in brittle failure or ductile failure [21-23]. Therefore, a comprehensive study on the crack propagation process under a compression load is needed as a basis for understanding the mechanism of the granite deterioration process. But the laboratory experiments can only reflect the strain change of rock as a whole, and it is difficult to study the strain inside the rock.

In order to solve the problems mentioned above, numerical simulation is extensively used to study the deformation behavior and fracturing process during loading. Besides, the heterogeneity of rock can be studied by using numerical simulation. Tang et al. conducted a numerical analysis to evaluate the effect of heterogeneity on the fracture processes and strength characterization of brittle materials [24-29]. It is shown that heterogeneity plays an important role in determining the mechanical behavior on both microscopic and macroscopic scale. $\mathrm{Li}$ and $\mathrm{Li}$ studied the influence of heterogeneity on mechanical and acoustic emission characteristics of rock specimen [30]. The results demonstrate that as the homogeneity increases, the peak strength and brittleness of rocks increase. Liu et al. investigated the fracture process of heterogeneous rock under various test techniques [31]. It indicates that rock heterogeneity has an important influence on the crack initiation location and the crack propagation path. Thus, the heterogeneity is considered to study the crack propagation of Beishan granite through numerical simulation. Furthermore, the strain inside the rock can be investigated.

Therefore, in this study, experimental tests are conducted to study the basic properties of Beishan granite. Parameters used in the numerical simulation are determined. In addition, the Weibull distribution is introduced to characterize the heterogeneity of rock in numerical simulation. Afterwards, a heterogeneous model of Beishan granite is built to study the deformation behavior and fracturing evolution during the complete failure process.

\section{Laboratory Tests Settings}

2.1. Preparation of Rock Specimens. The granite cores were taken from the Beishan area, Gansu Province, China. And it is mainly composed of approximately $33.7 \% \pm 5.8 \%$ plagioclase, $30.7 \% \pm 6.1 \% \mathrm{~K}$-feldspar, $28.6 \% \pm 8.0 \%$ quartz, and $7.1 \% \pm 4.8 \%$ biotite [32]. All the specimens were prepared based on ISRM recommendations [33]. Five specimens were prepared for the direct tensile test, three specimens were prepared for the uniaxial compression test, and five specimens were prepared for the conventional triaxial compression (CTC) test.

2.2. Test Facilities. As shown in Figure 1, a MTS815 Flex Test GT rock mechanics machine is used to conduct all the tests. The MTS815 experimental machine can provide a maximum load of $4,700 \mathrm{kN}$ and supply a maximum confining pressure up to $140 \mathrm{MPa}$. A pair of extensometers were used to measure axial and circumferential displacement during loading.

2.3. Testing Procedure. For the direct tensile test, the two ends of the specimen are bonded with the instrument with strong glue. During the loading process, the axial displacement was increased with a constant displacement rate of $0.005 \mathrm{~mm} / \mathrm{min}$ until the failure of the specimen.

For the uniaxial compression test, the axial stress was increased with a constant loading rate of $30 \mathrm{kN} / \mathrm{min}$ until the failure of the specimen.

For CTC tests, the confining pressures were set to 5, 10, 15,20 , and $30 \mathrm{MPa}$, respectively. First, to fix the position of the specimen, a vertical load of about $2 \mathrm{kN}$ was applied. Then, a constant loading rate of $0.05 \mathrm{MPa} / \mathrm{s}$ was applied to reach the designated confining pressure. Afterwards, the axial stress was increased with a constant loading rate of $30 \mathrm{kN} / \mathrm{min}$. Lateral deformation control was used when the axial stress approached the peak strength.

\section{Testing Results}

3.1. Results of Direct Tensile Tests. As shown in Figure 2, the trends of stress-strain curves under tension are basically the same, concaving upward. It indicates that the change rate of stress increases gradually under tension. When the tensile peak strength is reached, the tensile stress decreases sharply and the specimen is destroyed suddenly. The strength results are listed in Table 1, and the average tensile strength is about $8.66 \mathrm{MPa}$.

\subsection{Results of Uniaxial Compression Tests. As shown in} Figure 3, during the initial loading the axial stress increases slowly because of the closure of microcracks [34]. Afterwards, a linear relationship between axial stress and strain was observed during the following loading. When the peak stress is reached, macrocracks are formed along the axis direction, showing splitting failure. The obtained mechanical parameters are listed in Table 2.

\subsection{Results of Conventional Triaxial Compression Tests.} Figure 4 shows the stress-strain curves under CTC tests and also displays the failure patterns of Beishan granite. There is no doubt that the peak strength increases linearly with increasing confining pressure. The volumetric strain shows that the dilatancy threshold is about $81 \%$ of the peak 


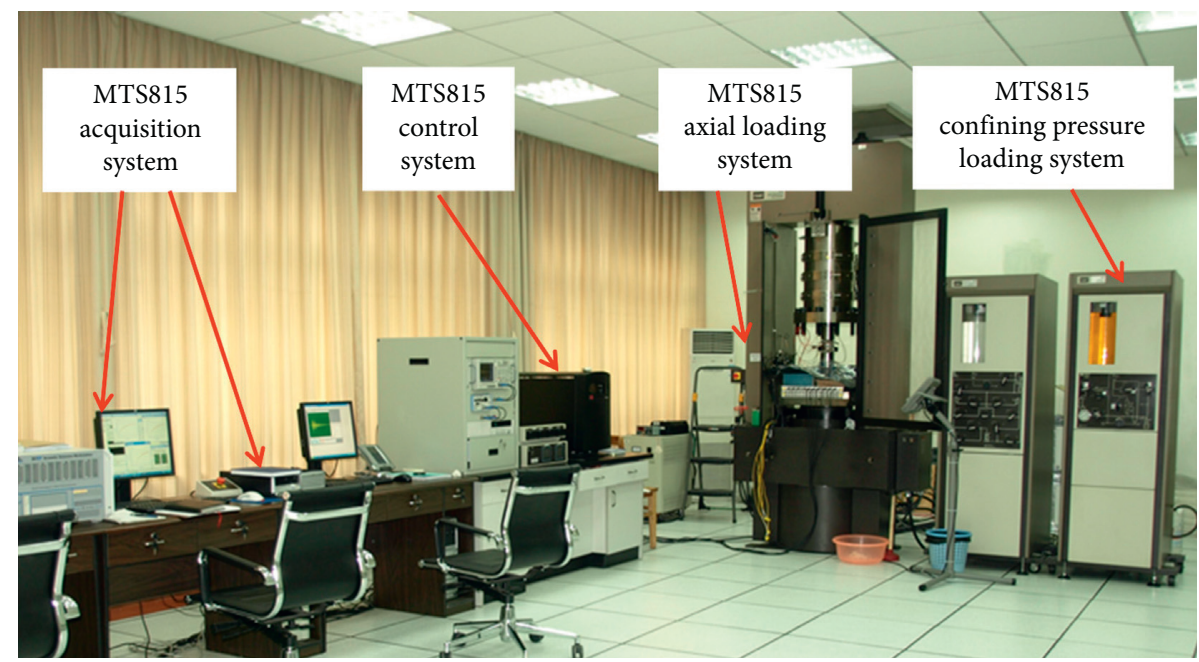

Figure 1: Rock mechanics experimental system of MTS815.

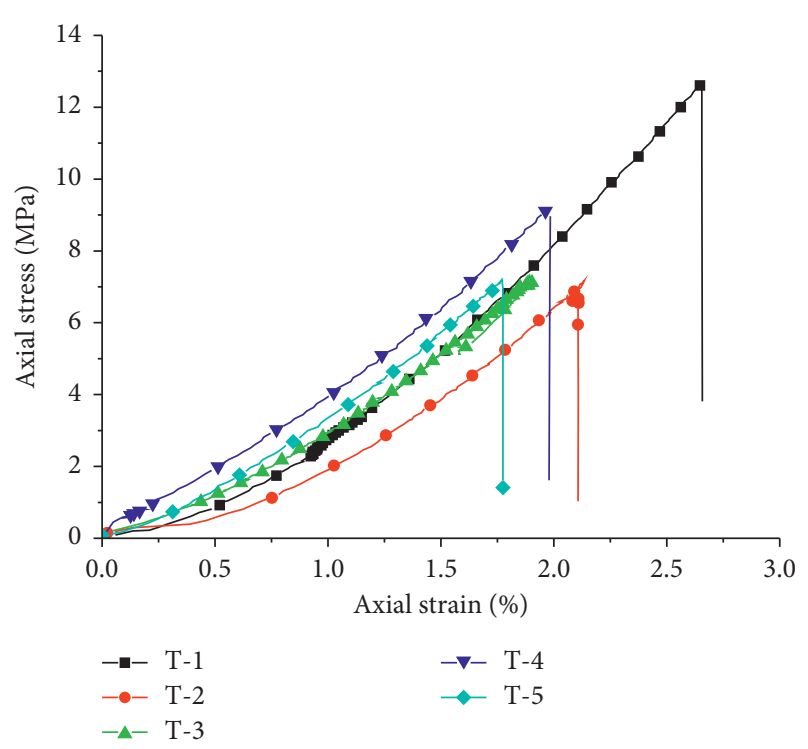

FIgURE 2: Stress-strain curves of Beishan granite for direct tensile test.

strength. It is worth noting that the specimen is still in a state of compaction after dilatancy threshold, compared with the initial specimen volume. The strength results and calculated mechanical parameters of Beishan granite are listed in Table 3.

\section{Introduction of Heterogeneity}

As an inhomogeneous material, rock is composed of different mineral particles. Besides, micropores and cracks are distributed randomly inside rocks. These individual components behave in different mechanical responses, leading to different deformation behaviors. Therefore, the stress and strain states can be dominated by the spatial distribution of these individual components during loading [35]. To solve this problem, the Weibull
TABle 1: Direct tensile test results of Beishan granite samples.

\begin{tabular}{lcc}
\hline Sample no. & Tensile strength $(\mathrm{MPa})$ & Average value $(\mathrm{MPa})$ \\
\hline $\mathrm{T}-1$ & 12.66 & \\
$\mathrm{~T}-2$ & 7.17 & \\
$\mathrm{~T}-3$ & 7.14 & 8.66 \\
$\mathrm{~T}-4$ & 9.11 & \\
$\mathrm{~T}-5$ & 7.20 & \\
\hline
\end{tabular}

distribution has been introduced to characterize the rock heterogeneity in numerical simulation works by many researchers [36].

The Weibull distribution is a continuous probability distribution. The general expression of Weibull probability density function can be written as

$$
f(x, \lambda, m)= \begin{cases}\frac{m}{\lambda}\left(\frac{x}{\lambda}\right)^{m-1} e^{-(x / \lambda)^{m}}, & x \geq 0, \\ 0, & x<0,\end{cases}
$$

with $x$ random variable, $m$ shape parameter, and $\lambda$ scale parameter.

The mean and variance of a Weibull random variable can be expressed as

$$
\begin{aligned}
& E(x)=\lambda \Gamma\left(1+\frac{1}{m}\right) \\
& D(x)=\lambda^{2}\left[\Gamma\left(1+\frac{2}{m}\right)-\Gamma\left(1+\frac{1}{m}\right)^{2}\right],
\end{aligned}
$$

where $\Gamma$ is the Gamma function.

The relationship between the scaled mathematical expectation $E(x) / \lambda$, dispersion $D(x) / \lambda^{2}$, and shape parameter $m$ is shown in Figure 5. As can be seen from Figure 5(a), with increasing shape parameter $m(m \geq 1)$, the scaled mathematical expectation approaches 1 , which means the scale parameter $\lambda$ is approximately the mean value of the Weibull distribution. When $\mathrm{m}$ goes towards infinity, the variance goes towards zero. Therefore, the shape parameter $m$ is also 


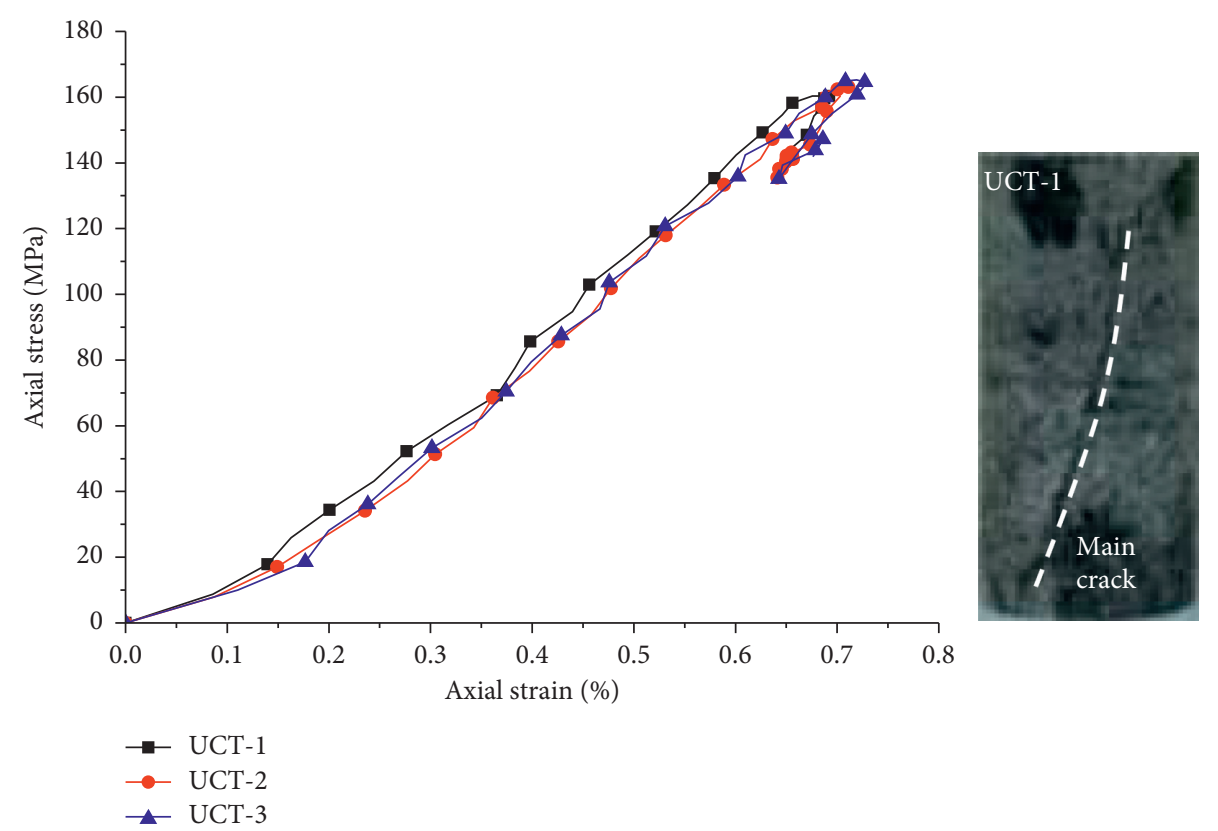

Figure 3: Stress-strain curves of Beishan granite for uniaxial compression test.

TABLe 2: Uniaxial compressive test results of Beishan granite samples.

\begin{tabular}{lccc}
\hline Sample no. & Peak strength $(\mathrm{MPa})$ & Young's modulus $(\mathrm{GPa})$ & Poisson's ratio \\
\hline UCT-1 & 160.5 & 30.1 & 0.123 \\
UCT-2 & 163.1 & 27.7 & 0.123 \\
UCT-3 & 165.2 & 27.9 & 0.120 \\
Average & 162.9 & 28.6 & 0.122 \\
\hline
\end{tabular}

defined as the homogeneity index and the scale parameter $\lambda$ is defined as the mean value of the physical parameter [37].

In the numerical simulation, mechanical parameters, such as the elastic modulus $E$, Poisson's ratio etc., obey the Weibull distribution with scale parameter $\lambda$ and shape parameter $m$. Based on the probability distribution $0 \leq F(x) \leq$ 1 , the Weibull distribution parameters can be generated from random numbers in $[0,1]$ :

$$
F(x)=\int_{0}^{+\infty} f(x) d x=1-e^{-(x / \lambda)^{m}} .
$$

The inverse function is

$$
x=F^{-1}(u)=\lambda[-\ln (1-u)]^{1 / k} .
$$

Based on equation (4), parameter $x$ is calculated.

\section{Numerical Simulation of CTC Tests}

5.1. Model Description and Setup. A cylindrical model (see Figure 6), characterized by heterogeneous, is built in FLAC $^{3 \mathrm{D}}$ to study the stress-strain state and fracture development inside the specimen during the complete failure process. The strain-softening model is chosen to simulate the mechanical response. The constant compressive displacement rate is set to $5 \mathrm{e}-8 \mathrm{~m} / \mathrm{step}$, which will be applied on end faces of the model in the following simulation. Based on the tests in Section 3 and reference [14], the input parameters are determined, as shown in Table 4. The validation of this numerical method has been proven by Tan [37].

5.2. Determination of Homogeneity Index $m$ of Beishan Granite. First, the homogeneity index $m$ of Beishan granite needs to be determined. Therefore, based on equation (4), models with different homogeneity index $m$ are established in FLAC ${ }^{3 D}$. For instance, the cohesion distribution with different homogeneity index $m$ is displayed in Figure 7 . Afterwards, these models are used to simulate the CTC test under confining pressure of $20 \mathrm{MPa}$.

The cohesion distribution after failure is shown in Figure 8, and 9 shows the simulated stress-strain curves. As demonstrated in Figure 8, the model has more degraded elements after failure when the homogeneity index is relatively low. In return, the model has fewer degraded elements when the homogeneity index is relatively high. Besides, the destroyed elements are more easily concentrate locally with a higher homogeneity index. Compared with the experimental results, the homogeneity $m=15$ is selected to conduct the CTC tests simulation.

\subsection{Simulation Results}

5.3.1. Failure Process. Figure 10 shows the obtained stressstrain curves, and the comparison between simulated strength and experimental strength is shown in Table 5. The 


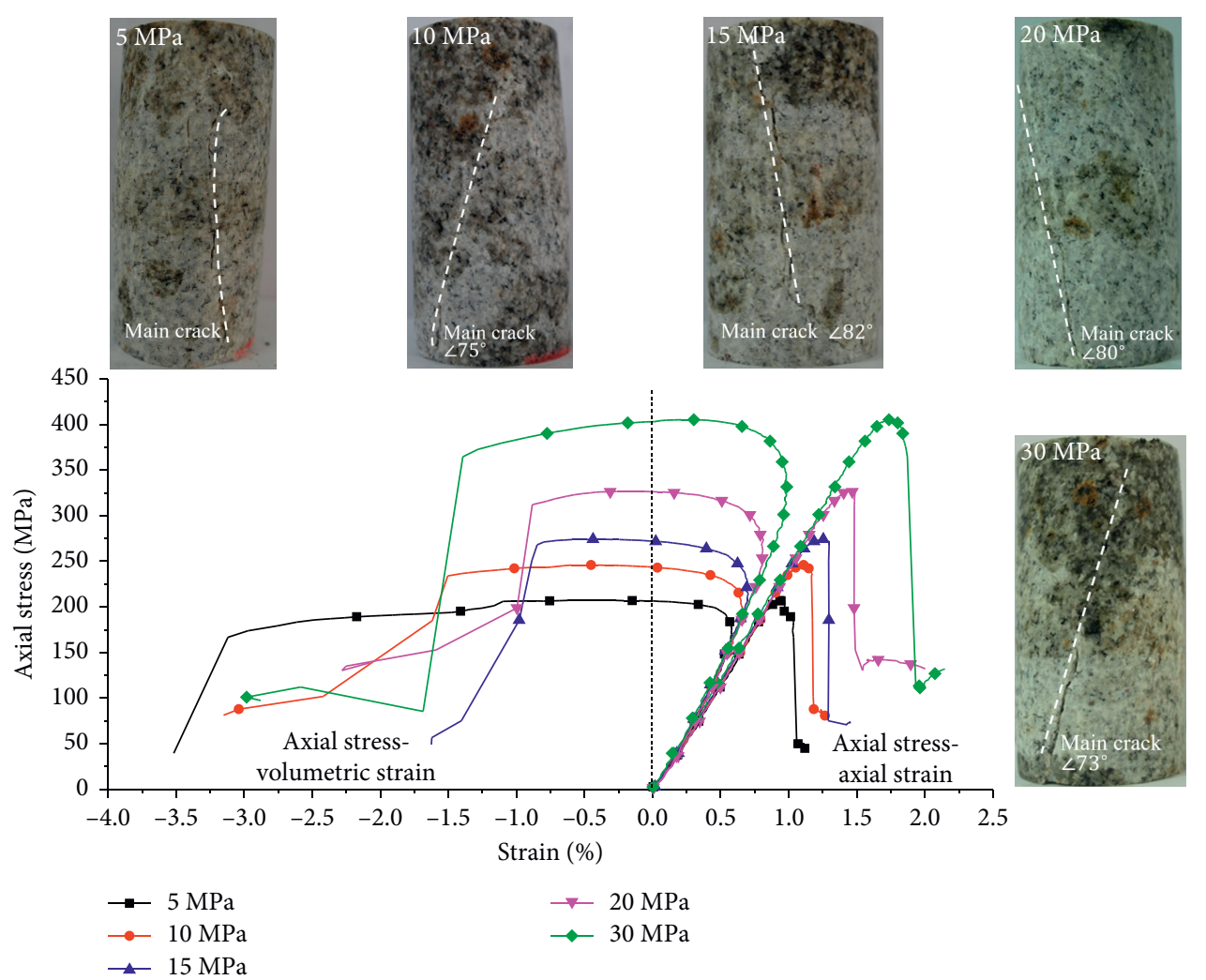

FIGURE 4: Stress-strain curves and failure patterns under different confining pressures.

TABle 3: Triaxial compressive test results of Beishan granite samples.

\begin{tabular}{|c|c|c|c|c|}
\hline Sample no. & Confining pressure $(\mathrm{MPa})$ & Peak strength $(\mathrm{MPa})$ & Cohesion $(\mathrm{MPa})$ & Friction $\left({ }^{\circ}\right)$ \\
\hline CTC -1 & 5 & 207.1 & & \\
\hline CTC -2 & 10 & 245.9 & & \\
\hline CTC-3 & 15 & 274.1 & 35.4 & 52.4 \\
\hline CTC-4 & 20 & 326.6 & & \\
\hline CTC-5 & 30 & 405.3 & & \\
\hline
\end{tabular}

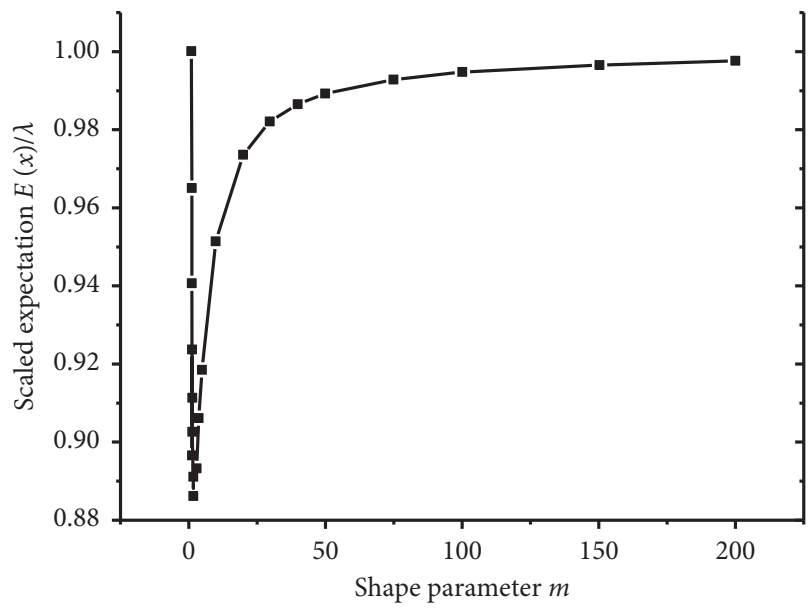

(a)

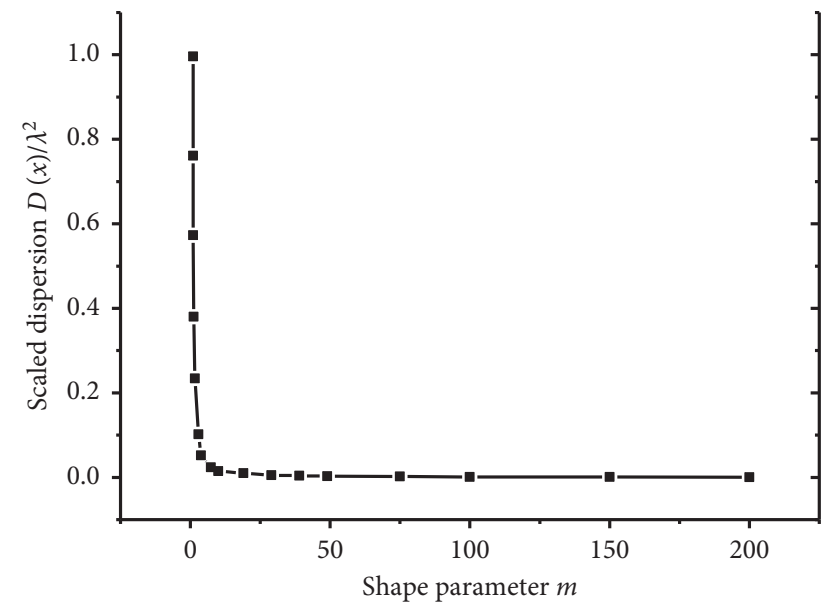

(b)

Figure 5: Scaled mathematical expectation (a) and dispersion (b) of the Weibull distribution with different shape parameters. 


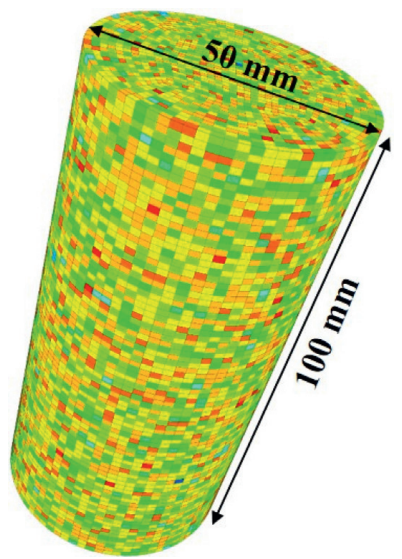

FIGURE 6: Schematic diagram of Beishan granite model [14].

TABle 4: Mechanical parameters of Beishan granite.

\begin{tabular}{|c|c|c|c|c|c|c|c|c|c|}
\hline \multirow[t]{2}{*}{ Elastic modulus/GPa } & \multirow{2}{*}{ Poisson's ratio } & \multirow{2}{*}{ Dilation $\left({ }^{\circ}\right)$} & \multirow{2}{*}{ Density $\left(\mathrm{kg} / \mathrm{m}^{3}\right)$} & \multicolumn{2}{|c|}{ Cohesion (MPa) } & \multicolumn{2}{|c|}{ Friction $\left({ }^{\circ}\right)$} & \multicolumn{2}{|c|}{ Tension $(\mathrm{MPa})$} \\
\hline & & & & Initial & Residual & Initial & Residual & Initial & Residual \\
\hline 28.6 & 0.122 & 17 & 2700 & 29.74 & 21.24 & 51 & 31.44 & 7.66 & 0 \\
\hline
\end{tabular}

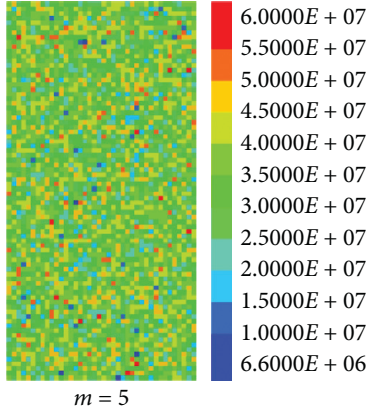

(a)

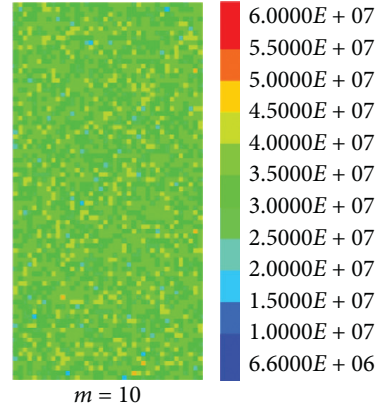

(b)

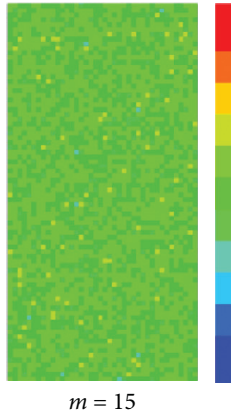

(c)

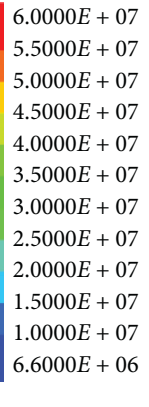

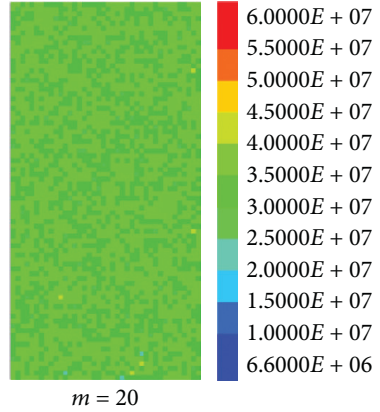

(d)

FIGURE 7: Cohesion distribution in models of Beishan granite with different homogeneity index $m$ (a) $m=5$. (b) $m=10$. (c) $m=15$. (d) $m=20$.

results indicate that the simulation for the CTC test is reliable. Taking confining pressure of $20 \mathrm{MPa}$ as an instance, the stress-strain states and fracture development observed at different points (shown in Figure 11) are displayed in Figures 12-15.

Some conclusions can be drawn based on the simulation results. During the pre-peak period from point $a$ to $c$, the model is undamaged. The volumetric strain value is negative and decreases all the time, which indicates that the element is in the state of compression. The shear strain has been increasing, but its value is relatively small. The stress distribution in the model is uniform, and the minimum principal stress increases gradually. The displacement develops basically along the axial direction, and there is no significant deviation. Therefore, during the pre-peak period, rock mainly shows elastic deformation.

At the peak stress (point $d$ ), near the model boundary a few elements begin to degrade. The volumetric strain of the elements near the model boundary starts to increase. The shear strain, stress distribution, and displacement also show slight changes at the same location, indicating the beginning of macrocrack generation.

In the stress drop stage from point $e$ to $h$, more and more elements are destroyed. The volumetric strain of most elements changes from negative to positive and increases rapidly, forming serval bands, which develop from the model boundary to the inside. In the meantime, shear strain bands develop rapidly at the same area. At point $h$, the shear band penetrating the whole model is formed. The tensile region appears in the model and is distributed in blocks along the shear bands. The displacement vector develops along the shear bands and outward at the boundary of the model.

In the residual stage from point $h$ to $k$, there are not new macrocracks. However, the volumetric strain shows sustained growth, so does shear strain. The formed strain bands 


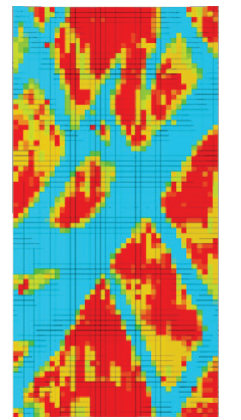

$m=5$

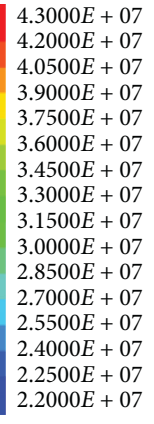

(a)

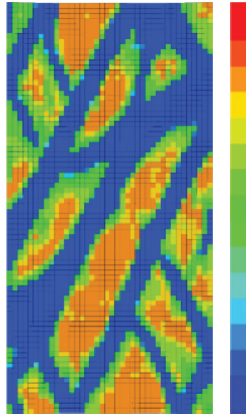

$m=10$

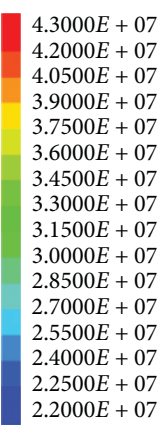

(b)

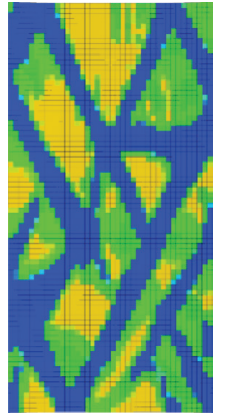

$m=15$

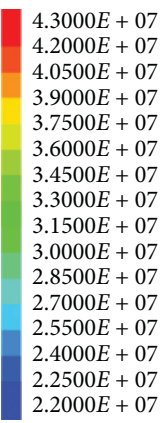

(c)

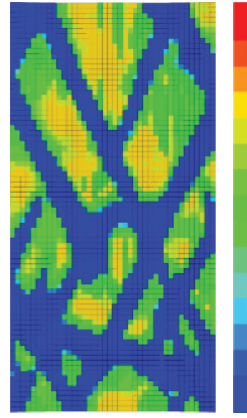

$4.3000 E+07$

$4.2000 E+07$

$4.0500 E+07$

$3.9000 E+07$

$3.7500 E+07$

$3.6000 E+07$

$3.4500 E+07$

$3.3000 E+07$

$3.0000 E+07$

$2.8500 E+07$

$2.7000 E+07$

$2.5500 E+07$

$2.4000 E+07$

$2.2500 E+07$

$2.2000 E+07$

$m=20$

(d)

FIGURE 8: Cohesion distribution in models after failure with different homogeneity $m$ under the confining pressure $20 \mathrm{MPa}$. (a) $m=5$. (b) $m=10$. (c) $m=15$. (d) $m=20$.

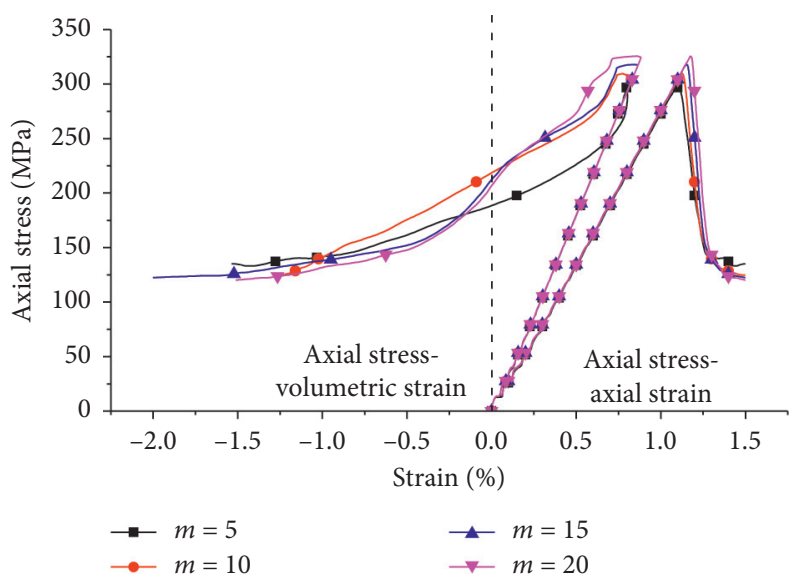

FIgURE 9: Simulated stress-strain relations for models with different homogeneity $m$ under the confining pressure $20 \mathrm{MPa}$.

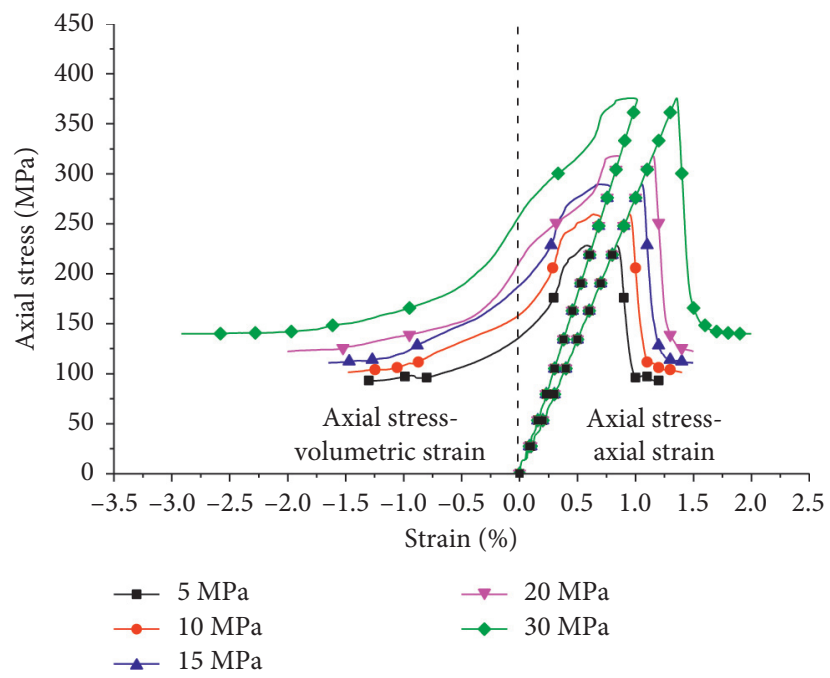

FIGURE 10: Simulated stress-strain curves for different confining pressures.

TABLE 5: The comparison between simulated strength and experimental strength.

\begin{tabular}{lccc}
\hline Confining pressure $(\mathrm{MPa})$ & Simulated strength $(\mathrm{MPa})$ & Experimental strength $(\mathrm{MPa})$ & Error $(\%)$ \\
\hline 5 & 237.0 & 207.1 & 12.62 \\
10 & 268.8 & 245.9 & 9.31 \\
15 & 298.6 & 274.1 & 8.94 \\
20 & 326.9 & 326.6 & 0.09 \\
30 & 384.6 & 405.3 & -5.11 \\
\hline
\end{tabular}




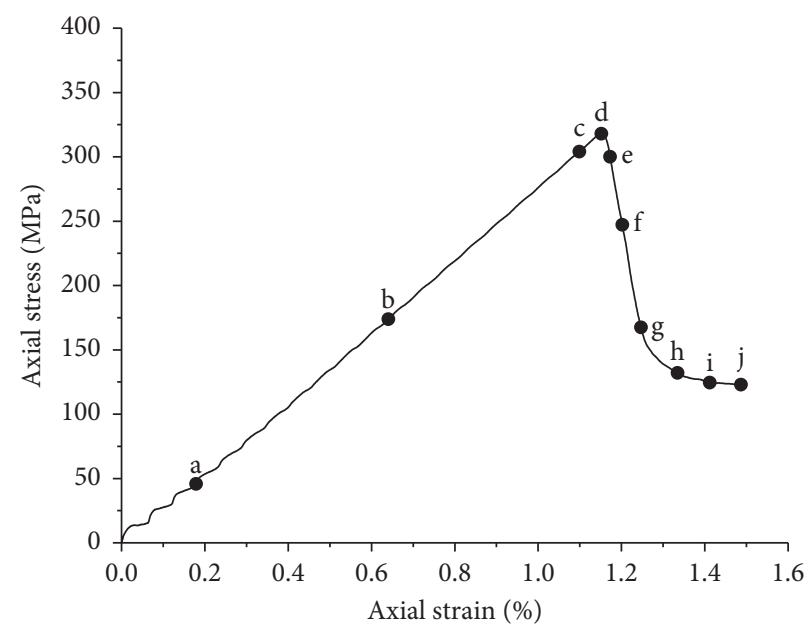

FIGURE 11: Simulated axial stress-strain curve under confining pressure of $20 \mathrm{MPa}$.

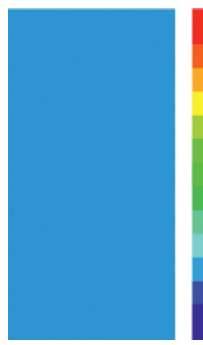

(a)

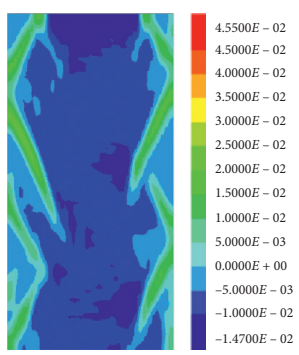

(f)

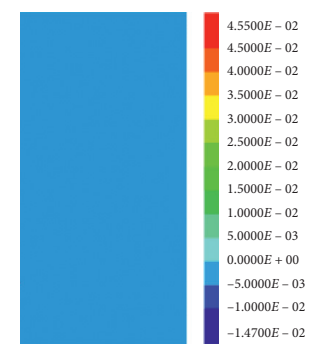

(b)

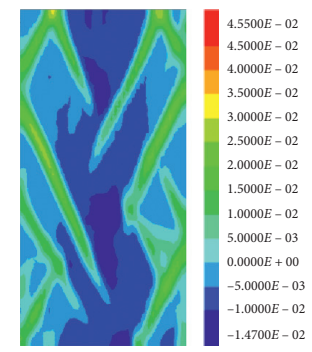

(g)

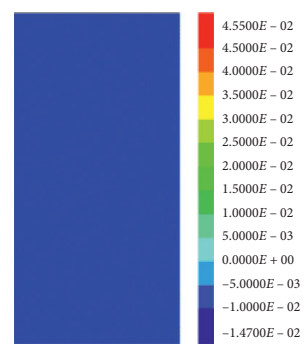

(c)

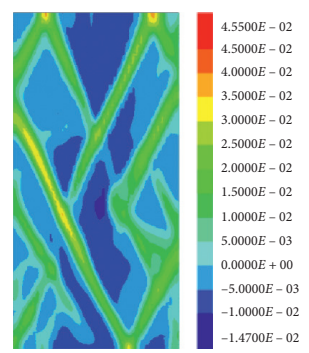

(h)

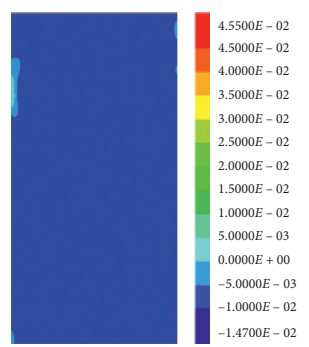

(d)

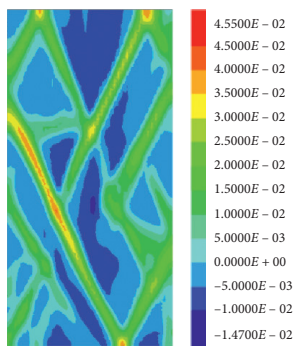

(i)

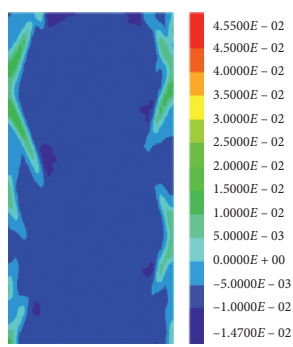

(e)

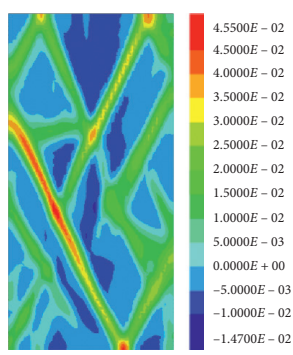

(j)

FIGURE 12: Volumetric strain evolvement at different stress level in simulated triaxial compression test under confining pressure of $20 \mathrm{MPa}$.

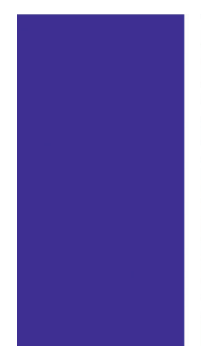

(a)

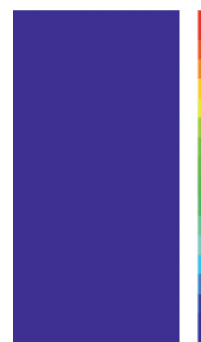

(b)

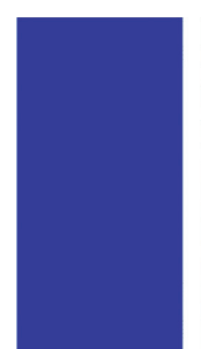

(c)

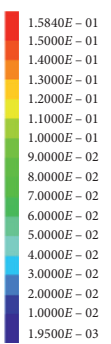

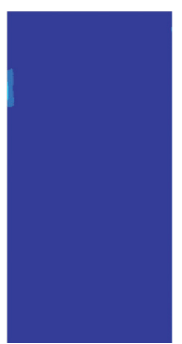

(d)

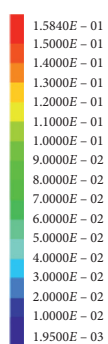

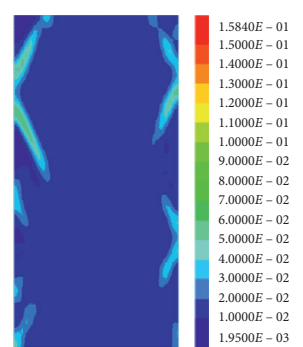

(e)

FIGURE 13: Continued. 


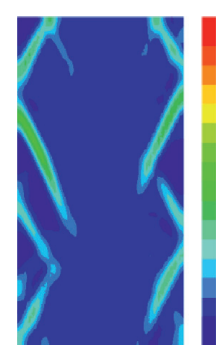

(f)

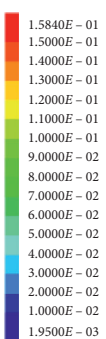

$2.0000 E-02$
$1.0000 E-02$

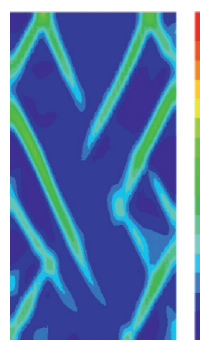

(g)

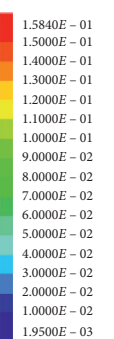

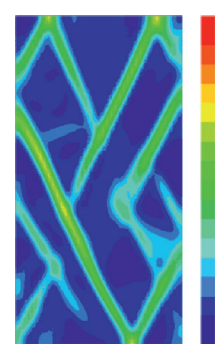

(h)

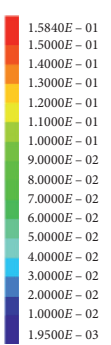

.

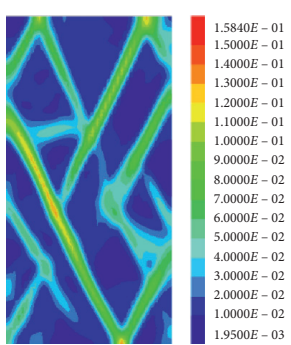

(i)

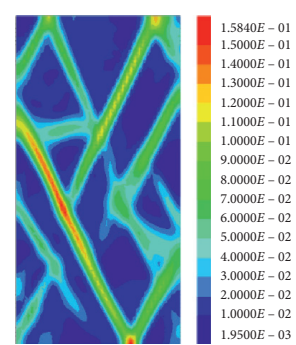

(j)

FiguRE 13: Shear strain evolvement at different stress level in simulated triaxial compression test under confining pressure of $20 \mathrm{MPa}$.

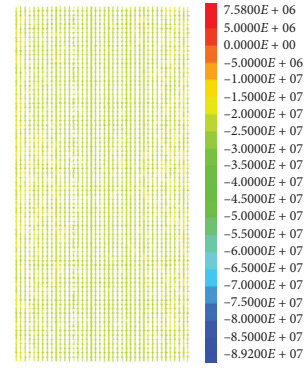

(a)

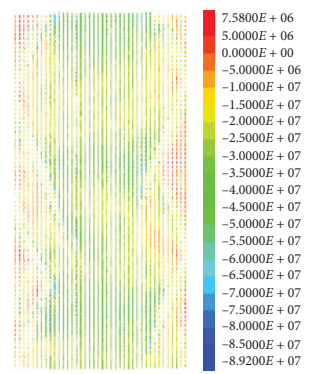

(f)

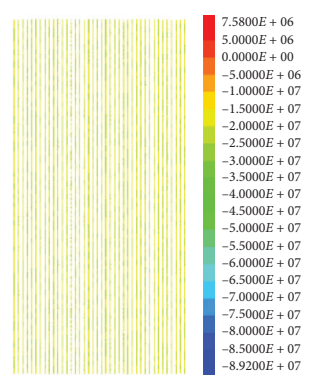

(b)

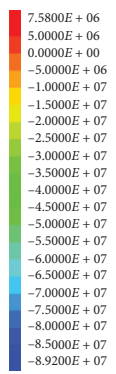

(g)

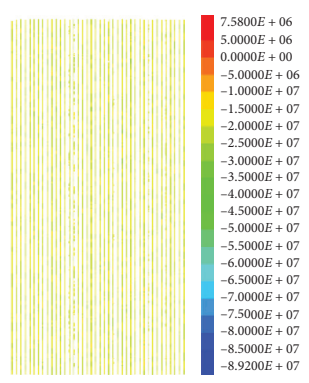

(c)

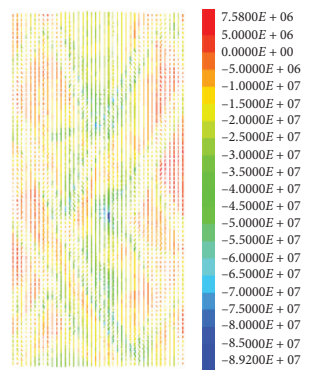

(h)

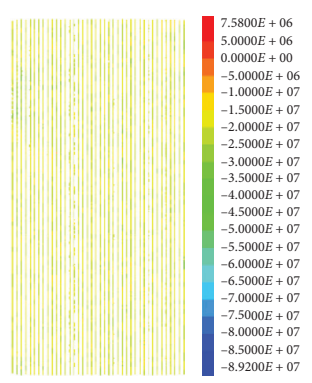

(d)

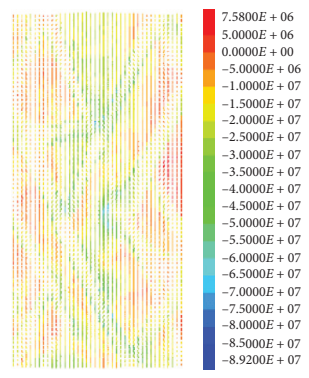

(i)

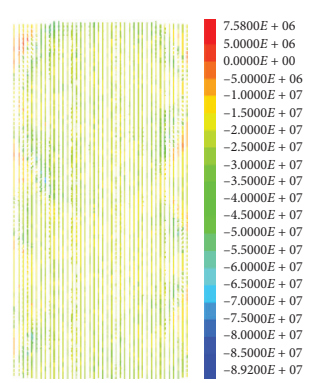

(e)

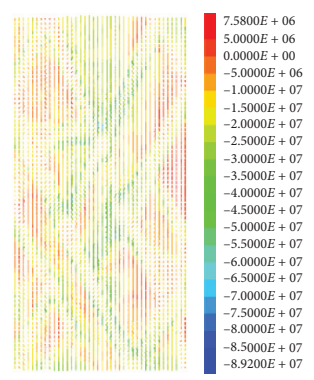

(j)

Figure 14: Minimum principal stress $(\mathrm{Pa})$ evolvement at different stress level in simulated triaxial compression test under confining pressure of $20 \mathrm{MPa}$.

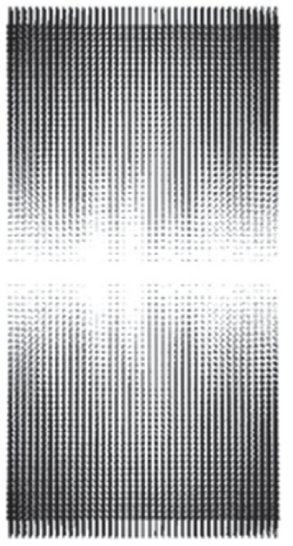

(a)
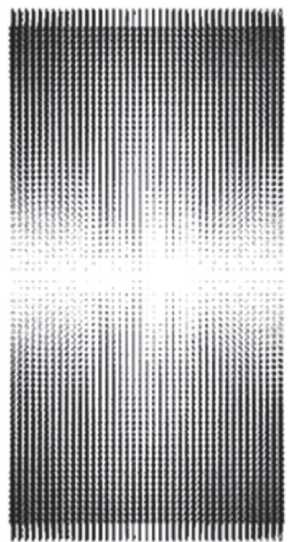

(b)
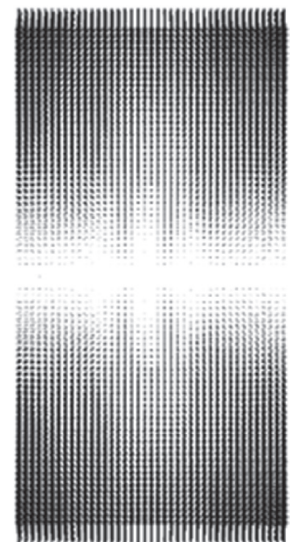

(c)
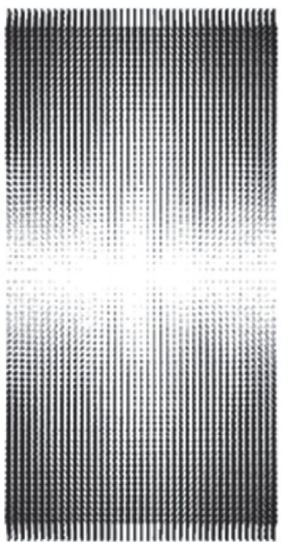

(d)
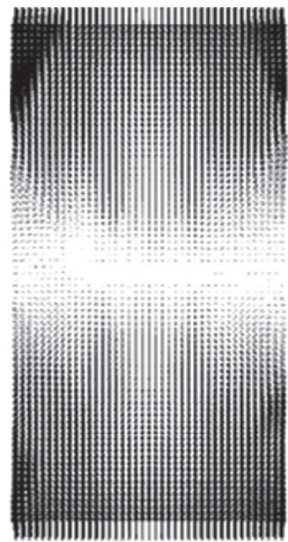

(e)

FIGURE 15: Continued. 


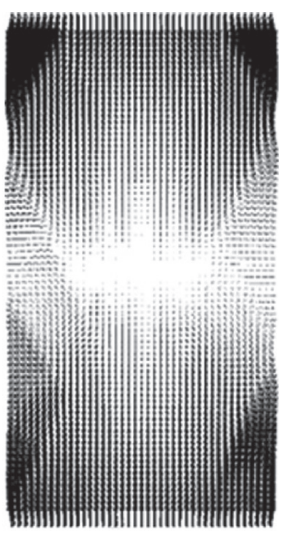

(f)

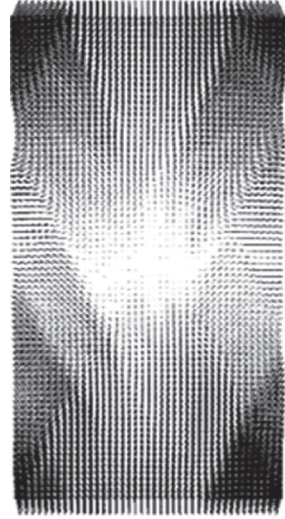

(g)

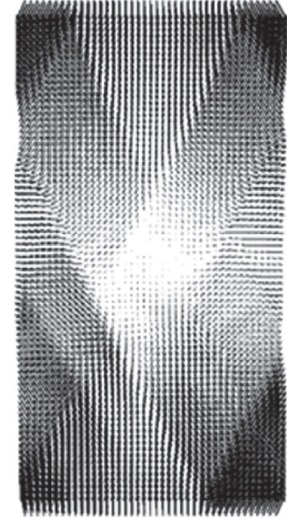

(h)

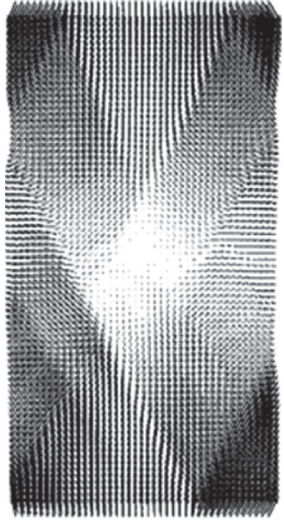

(i)

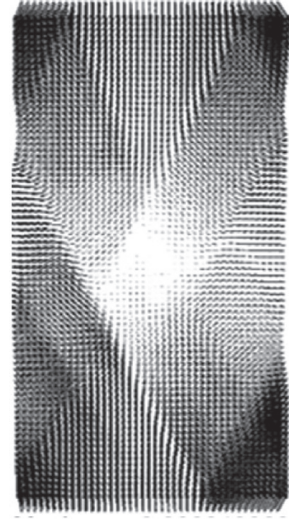

(j)

FIGURE 15: Displacement evolvement at different stress level in simulated triaxial compression test under confining pressure of $20 \mathrm{MPa}$

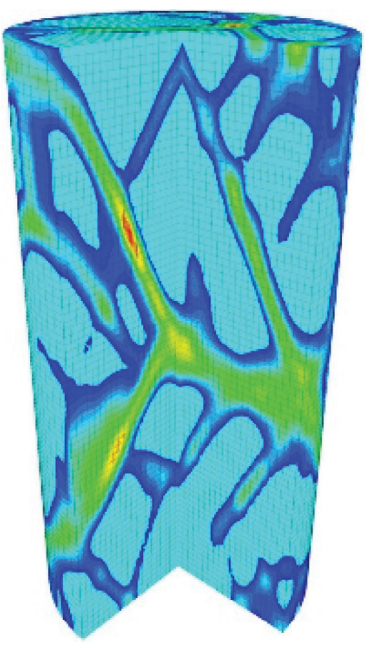

(a)
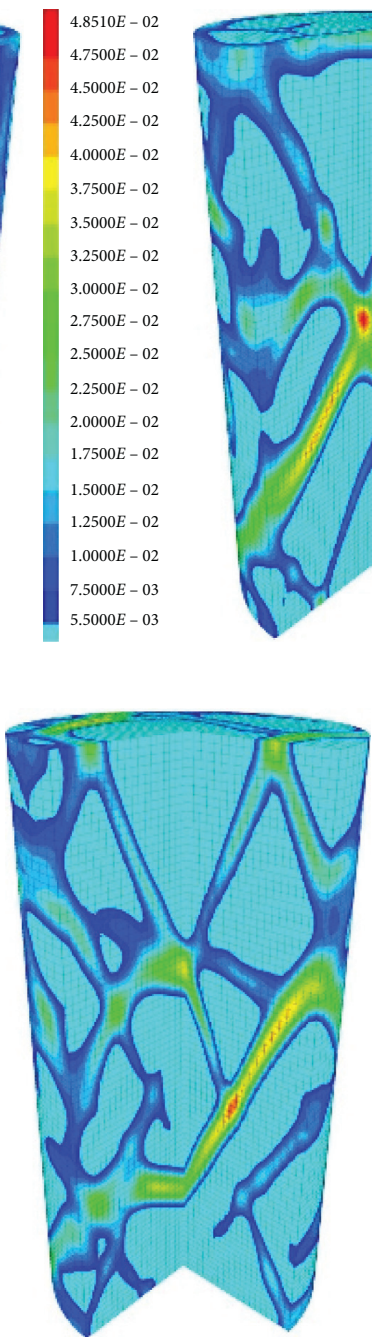

(d)

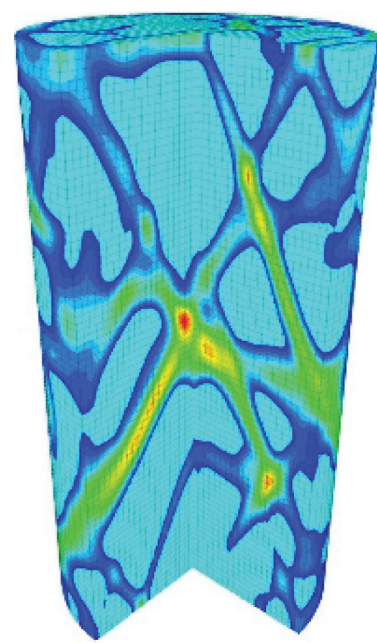

(b)

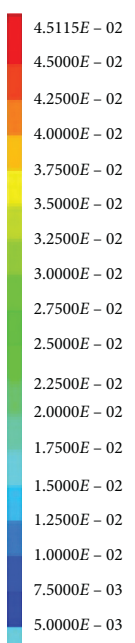

$4.5810 E-02$
$4.5000 E-02$
$4.2500 E-02$
$4.0000 E-02$
$3.7500 E-02$
$3.5000 E-02$
$3.2500 E-02$
$3.0000 E-02$
$2.7500 E-02$
$2.5000 E-02$
$2.2500 E-02$
$2.0000 E-02$
$1.7500 E-02$
$1.5000 E-02$
$1.2500 E-02$
$1.0000 E-02$
$7.5000 E-03$
$5.0000 E-03$

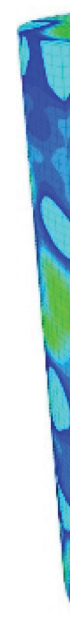

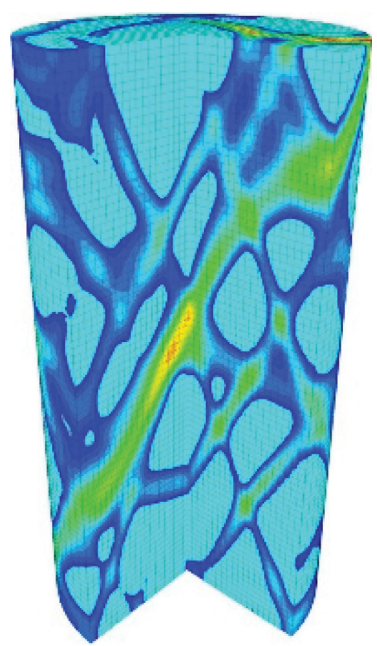

(c)

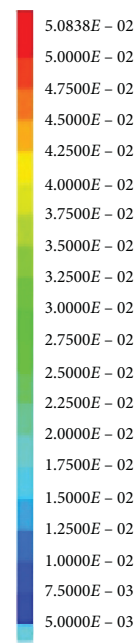

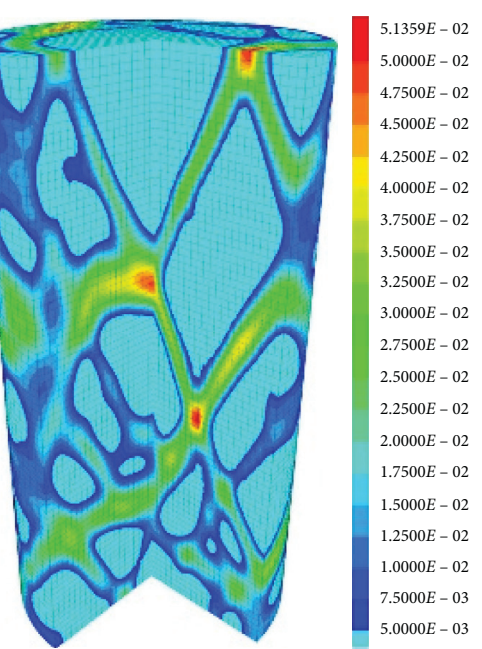

(e)

Figure 16: Volumetric strain ( $\varepsilon \mathrm{v}>0.5 \%$ ) after degradation under varied confining pressure. (a) $\sigma 3=5 \mathrm{MPa}$. (b) $\sigma 3=10 \mathrm{MPa}$. (c) $\sigma 3=15 \mathrm{MPa}$. (d) $\sigma 3=20 \mathrm{MPa}$. (e) $\sigma 3=30 \mathrm{MPa}$. 


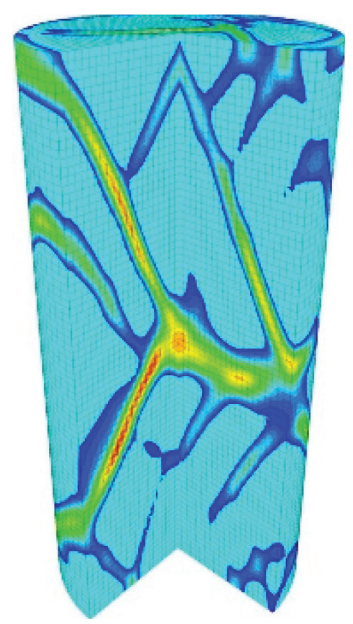

(a)
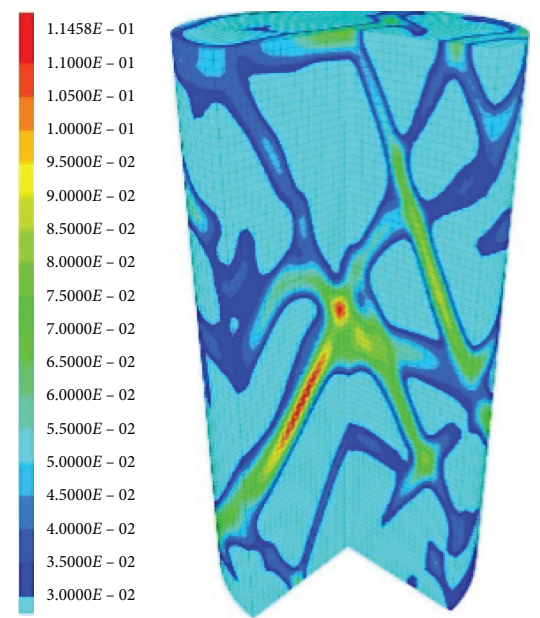

(b)

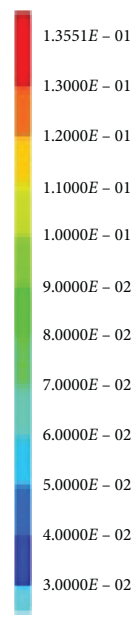

$1.6077 E-01$
$1.6000 E-01$
$1.5000 E-01$
$1.4000 E-01$
$1.3000 E-01$
$1.2000 E-01$
$1.1000 E-01$
$1.0000 E-01$
$9.0000 E-02$
$8.0000 E-02$
$7.0000 E-02$
$6.0000 E-02$
$5.0000 E-02$
$4.0000 E-02$
$3.0000 E-02$

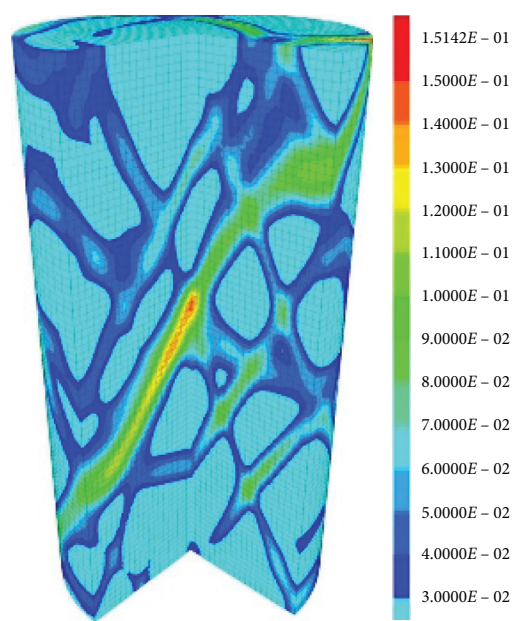

(c) (d)

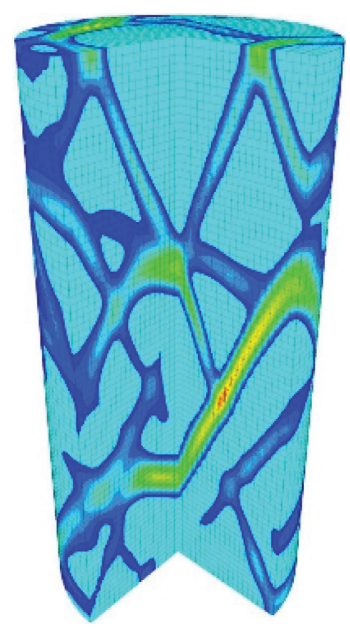

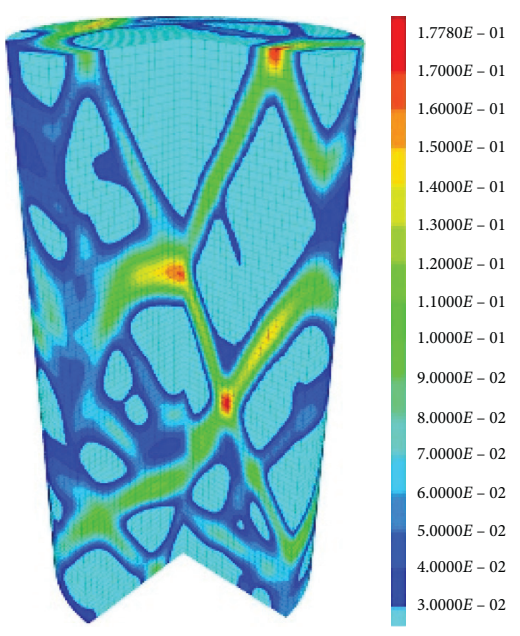

(e)

FIGURE 17: Shear strain $(\varepsilon s>2 \%$ ) after degradation under varied confining pressure. (a) $\sigma 3=5 \mathrm{MPa}$. (b) $\sigma 3=10 \mathrm{MPa}$. (c) $\sigma 3=15 \mathrm{MPa}$. (d) $\sigma 3=20 \mathrm{MPa}$. (e) $\sigma 3=30 \mathrm{MPa}$.

become wider. This means that the model has been destroyed.

5.3.2. The Effect of Confining Pressure. Figures 16 and 17 show the distribution of volumetric strain and shear strain in the model after failure under different confining pressures. It can be seen from Figures 16 and 17 that the elements in the fracture zone have large volumetric strain and shear strain. And with increasing confining pressure, the maximum volumetric strain remains relatively stable. However, the maximum shear strain increases with confining pressure. In addition, as the confining pressure increases, the shear failure surface becomes more regular. It can be concluded that the larger the confining pressure, the clearer the destroy angle. The deformation ability of the element, located in the destroy angle area, is strengthened. As a result, with the increase of confining pressure, the failure mode transforms from brittle splitting failure to ductile shear failure, which is consistent with the experimental result.

\section{Conclusion}

In this research, the strength and deformation processes of Beishan granite are obtained by experimental tests. The stress-strain state during the complete failure process is analyzed by numerical simulation. Based on the results, the following conclusions can be drawn.

The tensile strength and uniaxial compressive strength of Beishan granite are 8.66 and 162.9 MPa, respectively. Under triaxial compression, the dilatancy of Beishan granite appears when the stress reaches about $81 \%$ of the peak stress.

The heterogeneity of rock can be well introduced by Weibull distribution. With the increase of homogenization degree in numerical simulation, the degraded elements are more easily to concentrate locally.

The splitting failure dominates the destroy mode when the confining pressure is relatively low. With increasing confining pressure, more and more degraded elements are concentrated in the shear band, which develops from the surface to the interior of the sample during loading. Hence, 
the granite shows ductile mechanical response characteristics when the confining pressure is relatively high.

For the safety of HLW repository, more tests are needed for further investigating mechanical properties and fracturing characteristics of Beishan granite subjected to different conditions.

\section{Data Availability}

The data used to support the findings of this study are available from the corresponding author upon request.

\section{Conflicts of Interest}

The authors declare that they have no competing financial interests or personal relationships that could have influenced the work reported in this paper.

\section{Acknowledgments}

This work was supported by the National Natural Science Foundation of China (52074168 and 51874190), Major Program of Shandong Province Science and Technology Innovation Foundation (2019SDZY02), and China-APEC Cooperative Foundation in 2020, Major Program of Shandong Province Natural Science Foundation (ZR2018ZA0603).

\section{References}

[1] J. Wang, "On area-specific underground research laboratory for geological disposal of high-level radioactive waste in China," Journal of Rock Mechanics and Geotechnical Engineering, vol. 6, no. 2, pp. 99-104, 2014.

[2] J. F. Liu, H. Y. Ni, X. L. Cao, L. K. Ma, J. N. Guo, and X. Chen, "Laboratory investigation on gas permeability of compacted GMZ bentonite under a coupled hydraulic-mechanical effect,” Engineering Geology, vol. 276, Article ID 105761, 2020.

[3] J. Liu, S. Song, X. Cao et al., "Determination of full-scale pore size distribution of Gaomiaozi bentonite and its permeability prediction," Journal of Rock Mechanics and Geotechnical Engineering, vol. 12, no. 2, pp. 403-413, 2020.

[4] Z. T. Bieniawski, "Mechanism of brittle fracture of rock," International Journal of Rock Mechanics and Mining Sciences \& Geomechanics Abstracts, vol. 4, no. 4, pp. 407-423, 1967.

[5] W. R. Wawersik and W. F. Brace, "Post-failure behavior of a granite and diabase," Rock Mechanics and Rock Engineering, vol. 3, pp. 62-85, 1971.

[6] S. Peng and A. M. Johnson, "Crack growth and faulting in cylindrical specimens of Chelmsford granite," International Journal of Rock Mechanics and Mining Sciences and Geomechanics Abstracts, vol. 9, no. 1, pp. 37-86, 1972.

[7] K. Hadley, "Comparison of calculated and observed crack densities and seismic velocities in Westerly granite," Journal of Geophysical Research, vol. 81, no. 20, pp. 3484-3494, 1976.

[8] P. Tapponnier and W. F. Brace, "Development of stress-induced microcracks in Westerly granite," International Journal of Rock Mechanics and Mining Sciences and Geomechanics Abstracts, vol. 13, no. 4, pp. 103-112, 1976.

[9] R. L. Kranz, "Crack growth and development during creep of Barre granite," International Journal of Rock Mechanics and Mining Sciences \& Geomechanics Abstracts, vol. 16, no. 1, pp. 23-35, 1979.
[10] T. F. Wong, "Geometric probability approach to the characterization and analysis of microcracking in rocks," $\mathrm{Me}$ chanics of Materials, vol. 4, no. 3-4, pp. 261-276, 1985.

[11] M. Oda, T. Katsube, and T. Takemura, "Microcrack evolution and brittle failure of Inada granite in triaxial compression tests at $140 \mathrm{MPa}$," Journal of Geophysical Research-Solid Earth, vol. 107, no. B10, 2002.

[12] H. W. Zhou, Z. H. Wang, W. G. Ren, Z. L. Liu, and J. F. Liu, "Acoustic emission based mechanical behaviors of Beishan granite under conventional triaxial compression and hydromechanical coupling tests," International Journal of Rock Mechanics and Mining Science, vol. 123, Article ID 104125, 2019.

[13] H. W. Zhou, Z. H. Wang, C. S. Wang, and J. F. Liu, "On acoustic emission and post-peak energy evolution in Beishan granite under cyclic loading," Rock Mechanics and Rock Engineering, vol. 52, no. 1, pp. 283-288, 2019.

[14] Z. H. Wang, W. G. Ren, Y. L. Tan, and H. Konietzky, "Experimental and numerical study on hydromechanical coupled deformation behavior of beishan granite considering permeability evolution," Geofluids, Article ID 8855439, 14 pages, 2020.

[15] Z. H. Wang, T. Su, H. Konietzky, Y. L. Tan, and G. L. Zhou, "Hydraulic properties of Beishan granite after different high temperature treatments," Bulletin of Engineering Geology and the Environment, vol. 80, no. 4, pp. 2911-2923, 2021.

[16] Z. Zhou, Z. Li, C. Gao et al., "Peridynamic micro-elastoplastic constitutive model and its application in the failure analysis of rock masses," Computers and Geotechnics, vol. 132, Article ID 104037, 2021.

[17] W. F. Brace, B. W. Paulding, and C. Scholz, "Dilatancy in the fracture of crystalline rocks," Journal of Geophysical Research, vol. 71, no. 16, pp. 3939-3953, 1966.

[18] C. H. Scholz, "Microfracturing and the inelastic deformation of rock in compression," Journal of Geophysical Research, vol. 73, no. 4, pp. 1417-1432, 1968.

[19] W. F. Brace, "Volume changes during fracture and frictional sliding: a review," Rock Friction and Earthquake Prediction, vol. 116, no. 4-5, pp. 603-614, 1978.

[20] D. J. Holcomb, "Memory, relaxation, and microfracturing in dilatant rock," Journal of Geophysical Research: Solid Earth, vol. 86, no. B7, pp. 6235-6248, 1981.

[21] H. Haeard, "Transition from brittle fracture to ductile flow in Solenhofen limestone as a function of temperature, confining pressure, and interstitial fluid pressure," Geological Society of America Memoirs, vol. 79, pp. 193-226, 1960.

[22] H. Horii and S. Nemat-Nasser, "Brittle failure in compression: splitting faulting and brittle-ductile transition," Philosophical Transactions of the Royal Society A, vol. 319, no. 1549, pp. 337-374, 1986.

[23] T.-f. Wong, C. David, and W. Zhu, "The transition from brittle faulting to cataclastic flow in porous sandstones: mechanical deformation," Journal of Geophysical Research: Solid Earth, vol. 102, no. B2, pp. 3009-3025, 1997.

[24] C. Tang, "Numerical simulation of progressive rock failure and associated seismicity," International Journal of Rock Mechanics and Mining Sciences, vol. 34, no. 2, pp. 249-261, 1997.

[25] C. A. Tang and P. K. Kaiser, "Numerical simulation of cumulative damage and seismic energy release during brittle rock failure-Part I: fundamentals," International Journal of Rock Mechanics and Mining Sciences, vol. 35, no. 2, pp. 113-121, 1998. 
[26] P. K. Kaiser and C. A. Tang, "Numerical simulation of damage accumulation and seismic energy release during brittle rock failure-Part II: rib pillar collapse," International Journal of Rock Mechanics and Mining Sciences, vol. 35, no. 2, pp. 123-134, 1998.

[27] C. A. Tang, Y. F. Fu, S. Q. Kou, and P.-A. Lindqvist, "Numerical simulation of loading inhomogeneous rocks," International Journal of Rock Mechanics and Mining Sciences, vol. 35, no. 7, pp. 1001-1007, 1998.

[28] C. A. Tang, H. Liu, P. K. K. Lee, Y. Tsui, and L. G. Tham, "Numerical studies of the influence of microstructure on rock failure in uniaxial compression - Part I: effect of heterogeneity," International Journal of Rock Mechanics and Mining Sciences, vol. 37, no. 4, pp. 555-569, 2000.

[29] C. A. Tang, L. G. Tham, P. K. K. Lee, Y. Tsui, and H. Liu, "Numerical studies of the influence of microstructure on rock failure in uniaxial compression - Part II: constraint, slenderness and size effect," International Journal of Rock Mechanics and Mining Sciences, vol. 37, no. 4, pp. 571-583, 2000.

[30] S.-c. Li and G.-y. Li, "Effect of heterogeneity on mechanical and acoustic emission characteristics of rock specimen," Journal of Central South University of Technology, vol. 17, no. 5, pp. 1119-1124, 2010.

[31] H. Y. Liu, S. Q. Kou, P.-A. Lindqvist, and C. A. Tang, "Numerical modelling of the heterogeneous rock fracture process using various test techniques," Rock Mechanics and Rock Engineering, vol. 40, no. 2, pp. 107-144, 2007.

[32] X. G. Zhao, J. Wang, F. Chen et al., "Experimental investigations on the thermal conductivity characteristics of Beishan granitic rocks for China's HLW disposal," Tectonophysics, vol. 683, pp. 124-137, 2016.

[33] C. E. Fairhurst and J. A. Hudson, "Draft ISRM suggested method for the complete stress-strain curve for intact rock in uniaxial compression," International Journal of Rock Mechanics and Mining Science, vol. 36, no. 3, pp. 279-289, 1999.

[34] X. G. Zhao, M. Cai, J. Wang, and L. K. Ma, "Damage stress and acoustic emission characteristics of the Beishan granite," International Journal of Rock Mechanics and Mining Sciences, vol. 64, no. 12, pp. 258-269, 2013.

[35] X. Tan, H. Konietzky, and T. Frühwirt, "Numerical simulation of triaxial compression test for brittle rock sample using a modified constitutive law considering degradation and dilation behavior," Journal of Central South University, vol. 22, no. 8, pp. 3097-3107, 2015.

[36] H. Y. Liu, M. Roquete, S. Q. Kou, and P.-A. Lindqvist, "Characterization of rock heterogeneity and numerical verification," Engineering Geology, vol. 72, no. 1-2, pp. 89-119, 2004.

[37] X. Tan, "Hydro-mechanical coupled behavior of brittle rockslaboratory experiments and numerical simulations," Master Dissertation, Technische Universität Bergakademie Freiberg, Freiberg, Germany, 2013. 